\title{
Cleft Born Children: Families Perception
}

\section{Alina Dutta Roy ${ }^{1}$ and Aditi Nath ${ }^{2 *}$}

\author{
${ }^{1}$ Assistant Professor, Department of Social Work, NERIM, Guwahati, India \\ ${ }^{2}$ Assistant Professor, Department of Social Work, Assam University, Silchar, India \\ *Corresponding author: aditinath1@gmail.com
}

Received: 10 Sept., 2020

Revised: 24 Nov., 2020

Accepted: 11 Dec., 2020

\begin{abstract}
$\overline{\text { Cleft born children are perceived differently by different people in the society. Therefore, }}$ these children find them in difficult situations. Hence, the paper made an attempt to understand the perception of family members about the causes of cleft birth and the problems faced by the cleft children. For the study, thirty families of cleft born children who have undergone cleft surgery from comprehensive cleft care centre, Guwahati has been selected conveniently. Structured interview schedule as a primary tool of data collection was used when secondary sources were like journals, reports, and websites. The study found that the causes held responsible for cleft birth by the family members are associated with superstitious belief which was debarring cleft children to receive proper treatment from the family. The study also found that the same cleft lip children are treated differently by the families after surgery. The family members feel surprised and happy seeing the cleft child like normal child. The lack of awareness about the genuine causes responsible for cleft birth among family members is creating mental stress among the parents of cleft children. Hence, the study suggested that there is a need to have proper awareness of the problems and the treatment procedures so that more and more people can get acquainted with cleft and treat it as a "birth disorder" which is curable.
\end{abstract}

Keywords: Cleft, deformity, perception, family, community

Cleft is a congenital disease that leaves a gap in the tissue of the lips or palate leading to a deformity. Cleft lip and cleft palate is also known as Orofacial cleft. A cleft palate is a condition in which the roof of the mouth has an opening till the nose. Cleft is the second most common cleft deformity occurring

How to cite this article: Roy, A.D. and Nath, A. (2020). Cleft Born Children: Families Perception. Learning Community, 11(2): 63-69. 
in babies (Mossey, P. 2009). According to GOI, the prevalence of cleft lip and palate is 0.93 for every 1000 live births. Cleft palate alone occurs in 0.17 for every 1000 live births (IPDTOC, 2011). In Assam, the estimated number of clefts is a figure which varies in the range of 10,000 to 15,000 being the backlog of patients in the State and around 1000 to 1200 patients being born every year (Govt. of Assam). Cleft deformity is most common in the villages and backward areas where medical resources are limited and also problems like poverty, illiteracy and superstition are dominant. Widespread sociocultural beliefs add to the problem. In India, the cleft is not only a medical issue but it hugely creates social and psychological problems for the patient and their families. Socially, Cleft deformities deprive children of a life of dignity and opportunity for their future. Though cleft is a corrective deformity, yet access to quality care and treatment is very low. Without curative surgery, these children struggle to speak, eat, and eventually failed to participate in society. Trapped within their bodies, they lose out on education and livelihood and remain in the periphery of their society, deprived of basic human dignity. A girl child born with a cleft is neglected even by their own families and is often dumped at orphanages. Families are often ashamed of cleft born and sometimes consider them as ill-luck for the family. Even in communities, these children are taunted and often schools do not accept them. Cleft is not life-threatening; children born with cleft defects are subjected to a life where they grow up as social outcasts and objects of ridicule. If cleft is not treated, the patient has to suffer many associated physical and psychological problems. According to World Health Organization (WHO) study in India 1 in every 700 children are born with cleft lip or cleft palate deformities. In India, 35,000 children are born with cleft deformity annually. In India, It is estimated that a backlog of 1 million untreated cleft children and young adults are waiting for their chance of a free cost surgery. Millions need help, but cannot access care either for non-availability of services or for ignorance. It is observed that a person living with untreated cleft never comes to the mainstream of life. Poor health, physical look, poor speech, lack of education demoralizes his/her entire life. Girls hardly get married, boys hardly could establish themselves; they remain behind as a second class citizen. Health wise, a person with an untreated cleft has an expected life span that's statistically 14 years less than the national average. Cleft of the palate leads to speech delay. These children may take longer time to talk. When they do, they may talk slower than most children with a cracking voice which becomes a major barrier in their institutional education. Society doesn't like to accept them and does gradually damage the charm of living. Mother of cleft children often face social trauma. Starting from her husband to in-laws; to neighbours she is targeted and abuse for giving a cleft birth. Many times she is forced to leave her husband home and take shelter to her mother's house. Hence, the study was conducted to understand more in detail about the perception of families about cleft birth.

\section{Consulted Literature}

Chapman 1993 carried out a study to examine the psychological impact the cleft deformity has on 5-year-old children. He explained how such children are always the centre of attention which fills them with curiosity and shyness. Richman 2006 conducted a similar study to understand the behavioural aspects of school-going cleft children. His study explained how in schools the cleft children create 
different perceptions and attitudes among teachers and peer groups for the deformity that they carry and which lowers their self-esteem. Both the study was based on toddlers and school going and the impact on families and the community was not very elaborate. Kosowski, Weathers, Erik, and Ridgway (2012) explained, in particular, the speech problem that a cleft palate child has and how important the speech therapy is, along with cleft surgery for complete treatment of the child. Abeer \& Abrar (2018) stressed the effects cleft born has on the parents and speaks about the social support the family receives. Felman (2018) very clearly explained what is cleft and its other medical conditions and treatments. It explained very clearly the medical problem associated with cleft and surgery as a remedy. However, limited literature had highlighted about the life of cleft children in post surgery context. The study covered the impacts created a by a cleft child in the family but limited studies are found on how the families perceive the cleft birth. Therefore the study made an effort to understand families perception about cleft birth.

\section{Study Area}

The present study has been conducted in the Guwahati City of Assam. It is estimated that in Assam approximately 15,000 patients are living with untreated cleft lips or cleft palates (according to estimated figures from the Government of Assam) which needs required intervention. In response, The Assam State Government resolved to create a cleft free state in partnership with Operation Smile through Public Private Partnership Model in May 2009. To fulfill the vision of "Cleft Free State", a comprehensive Cleft and Child Care Centre has been set up at the Mohendra Mohan Choudhury Hospital, Guwahati in 2011 for providing year round surgical care to patients with cleft deformities. This centre is conceived to be a state-of-the art cleft care centre matching global standards to provide comprehensive care to patients of Assam did surgery to more than 20000 cleft children of different states of North East.

\section{Methodology}

The study has been conducted based on the responses of family members having cleft children. The descriptive study design tried to understand the perception of family members about cleft birth along with the problems faced by cleft birth children. For the study, thirty families of cleft born children who have undergone cleft surgery from comprehensive cleft care centre, Guwahati has been selected conveniently. From those select families, parents of the cleft child were interviewed. The objective of the study was to understand the perception of the family members about the causes responsible for cleft birth and also to understand the attitude of the family members towards cleft born child along with the problems faced by the cleft child. The interview schedule as a tool was used for collecting primary data and the secondary sources of data used in the study are journals, reports, websites and scholarly articles. The findings of the study have been presented through statistical data. 


\section{RESULTS AND DISCUSSION}

\section{Demographic Profile of the cleft born family}

The study explored that $63 \%$ families had nuclear family structure and $37 \%$ joint family structure. On dividing families having cleft children as per their caste, it was found that $6 \%$ of the families were from OBC; $11 \%$ from General category; $19 \%$ from Scheduled Cast; $28 \%$ from MOBC and $36 \%$ of the respondents were from Schedule tribe category. While understanding their family income, the researcher found that the families belonged to a lower income group. Based on the responses, the monthly family income was classified into three groups, viz., (i) below ₹ 10000, (ii) between ₹ 10000 to ₹ 20000 and iii) above ₹ $20000.57 \%$ of the families were from lower-income groups i.e. below Rs $10000.43 \%$ of the families had monthly income between ₹ 10000 to ₹ 20000 . However, none of the families had their monthly income above ₹ 20000. This explains that the incidence of the cleft is more among lowerincome groups owing to their ignorance, lack of knowledge, and limited access to proper health care.

\section{Cleft born children according to their age and gender}

The age and gender of the cleft children were studied. A cleft born usually has cleft lip surgery after the age of 6 months and cleft palate surgery after the age of 1 year. Early surgery is advisable for the elimination of any complication or scars. Keeping these criteria in mind the age group of the cleft children was divided into three groups i.e. (i) 6 months to below year, (ii) 1 year to 2 years, (iii) 2 years above. The findings reveal that $51 \%$ of the families had cleft children between the age group of 1-2 years. Among the cleft children 57\% were male and $43 \%$ female. Cleft can happen to any child irrespective of gender but in the society a cleft girl child is found more vulnerable than they male. A cleft in the female is pitied upon, made to feel ugly and hence lowering their self confidence and also putting them into depression as they grow. In future they do also remain unmarried adding to the worries of their families.

\section{Families perception about cleft birth}

From among the family members, the parents were asked to share their opinion about the causes of cleft birth. The question was asked to understand the level of awareness about the problem. Responses indicated that the family members perceived cleft born child as the reincarnation of Lord Ganesha and is happy with the cleft birth which they feel bright good luck upon them (3.33\%). 16.67\% believes that the cleft birth is the result of some past deed of the family members. $20 \%$ of families however still believe it's a natural process and naturally curable and are bonded by superstitious belief. $23.33 \%$ have accepted it as a God's gift therefore they are not worried. However, 36.67\% have stated a common reason and that is associated with the eclipse. They feel the mother has not maintained traditional rules and have come out during the eclipses and hence the child is cleft born. The family members were again asked to share their opinion about the first reaction that they had seeing the cleft birth child. The question was asked to understand the attitude of the family members towards the cleft birth child. Responses of 
the family members indicated that the $18 \%$ of the family members reacted with fear seeing the cleft child. $33 \%$ of the families were depressed and $28 \%$ considered cleft child as burden of the family, $9 \%$ showed curiosity to know more about cleft birth when $11 \%$ families thought of searching out possible treatment avenues for cleft children. The families were asked to share feeling about cleft child after surgery. The question was asked to understand whether the attitude of the family members have changed towards cleft child after surgery or not. Responses indicated that $100 \%$ of them felt surprise and happy seeing the cleft child like normal child.

\section{Problems faced by the cleft born Children}

The family members were asked to share their opinion about the problems faced by their cleft child. The question was asked to understand how far family members are aware about the issues associated with cleft child. Responses indicated that the children are facing physiological as well as psychological issues which are explained below.

\section{Physiological Problems}

Due to abnormality occurring in the joining of the lip and/ or palate, feeding a cleft baby becomes a concerning issue for the parents. While trying to feed liquid often spills out from the mouth and enters the nose of the baby. The study found that $16 \%$ of the children are having a feeding problem. So the parents have to be very cautious during feeding. Due to incapability to feed properly the cleft patients often suffer malnutrition which gets fatal with time. Cleft babies are experiencing trouble swallowing food. It is found that $12 \%$ children often flows back food into the nose and creates a blockage for the air to pass. The untreated cleft palate is leading to speech problems resulting in nasal-voiced speech and/ or unclear vocal sound when the baby turns a little older. After palate surgery, the patient needs speech therapy to improve their speech. $32 \%$ of the children are having difficulty in speech and these are mainly the cleft palate patients. $19 \%$ cleft afflicted children are found suffering from ear infections. Due to the passing back of food through the nasal passage, often the liquid gets accumulated in the ear and causes ear infection. Cleft-afflicted children commonly experience dental problems like missing teeth, small size teeth or even deformed and extra teeth, gum problems, dislodge teeth, etc. such patients also have cavities and need orthodontic treatments. The present study found that $21 \%$ of the cleft children are with dental issues.

\section{Psychological problems}

Psychological pressure is created within an individual is labelled different from being normal. The cleft birth of a child brings many questions, emotions, and opinions among the families. An individual is conscious towards their body image and this affects their thoughts, feelings, and behaviour. If perceived negatively, they suffer from low confidence and morale. Widespread socio-cultural beliefs add to the problem. Even when they are brought home, their families are ashamed of them, other children taunt them and most schools won't accept them. They also face problems in getting a decent job, are rejected 
in marriage, and are unable to cope with normal social activities. Though 'normal' in every other sense, children born with cleft defects are condemned to grow up as social outcasts and objects of ridicule because of the facial deformity and speech impediment. As per data, 12\% of the children are affected by low self-esteem and these are mainly the children above 2 years of age. It has been observed during interaction with the parents that after surgery the physiological problems of the children get lessened. The children with speech deformities show good developments after attending speech therapy sessions.

\section{DISCUSSION}

Cleft has become a very common congenital problem these days. Though not life-threatening yet it kills the person socially, psychologically and also many physical problems are associated with it. If treated early, the children are saved from social stigma and psychological pressure as they grow. The ideal age for treatment is 6 months to 1 year. The study revealed that the families perceive the cause of cleft to be related to superstitious beliefs and are usually depressed and sad. They are yet to acknowledge the fact that cleft may be the result of improper care during pregnancy, malnutrition, excessive medication, etc. These beliefs obstruct their thinking and instead of taking precautions and extending care in pregnancy, the families are more concerned with maintaining traditional rules and superstitions associated with childbirth to prevent cleft. The communities also take pity on the family and welcome the child with utter despair which ultimately harms the development of the children. However, the cleft is curable and govt. along with medical charities have come forward to treat cleft with proper surgery and comprehensive care. Such surgeries are also free of cost made available to them. There is a need to have proper awareness of the problems and the treatment procedures so that more and more people can get acquainted with cleft and treat it as a "birth disorder" which is curable.

\section{CONCLUSION}

The statistics reveals that cleft lip and palate deformity is one of the most common deformities among Indian children. Millions need help, but cannot access care either for non-availability of services or for ignorance. Due to abnormality occurring in the joining of the lip and/ or palate, feeding a cleft baby becomes a concerning issue for the parents. Discriminating and embedding the feelings of being different from normal creates social stigma in an individual. A negative response from outsiders, actual or perceived, may adversely affect self-image. Widespread socio-cultural beliefs add to the problem. However, there is a need to create mass awareness among the community and change the belief system that cleft is not a result of any eclipse or other religious beliefs rather it's a natural problem that is curable with surgery. The surgery needs to be made available at free of cost and early treatment should be encouraged for the removal of scars and encourage the child to grow with self-confidence. Every child has a right to live happily in a civilized society. When a cleft child is born he/she has a future of uncertainty, which they don't deserve. A surgery changes their life, brings smiles to their family, give them a future of hope just like other children, and strengthen our country's health scenario. Hence the family needs to be counselled for surgery. Any cleft born should immediately be informed to the local health centres that in turn can refer them to the proper centre. 


\section{REFERENCES}

1. Barker, E.I. 1951. A study of certain aspects of personality in given individuals having cleft palate, M. S. Thesis, University of Michigan.

2. Birrig, A.L. 1951. A psychological appraisal of cleft palate patients, Proc. Penn, Acad. of Sci., 25: 29-32.

3. Chapman, K.L. 1993. Phonologic Processes in Children with Cleft Palate, Case Western Reserve University, Cleveland, Ohio, Retrieved from https://journals.sagepub.com/doi/abs/10.1597/1545-1569_1993_030_0064_ ppicwc_2.3.co_2

4. CORAH, N.L. and Coran, P.S. 1963. A study of body image in children with cleft palate and cleft lip, J. Genet. Psych., 103: 133-173.

5. Felman, A. 2018. Cleft Lip \& Cleft palate, retrived at https://www.medicalnewstoday.com/articles/164660

6. IPDTOC, 2011. Prevalence at birth of Cleft lip with or without cleft palate, retrieved from https://pubmed.ncbi. nlm.nih.gov/20507242/

7. Kosowski, T.R., Weathers, W.M.,Wolfswinkel, Erik, M., Ridgway and Emily, B. 2012. Cleft Palate. Semin Plast Surg., 26(4): 164-169.

8. Mossey, P. 2009. Addressing the Challenges of Cleft Lip and Palate Research in India, Indian Journal of Plastic Surgery, pp. 9-18.

9. Namankany, A. and Alhubaishi, A. 2018. Effects of cleft lip and palate on children's psychological health: A systematic review, Retrieved from 10.1016/j.jtumed.2018.04.007

10. Reddy, G.S. 2010. Incidence of Cleft Lip and Palate in the state of Andhra Pradesh, Indian Journal of Plastic Surgery, 43(2):184-189. 
